\title{
Long-Time Performance of a Stainless Steel Crossflow Filter with Simulated Hanford Tank Waste
}

Philip P. Schonewill*, Richard C. Daniel, Rick W. Shimskey, Carolyn A. Burns, Justin M. Billing, and Reid A. Peterson

Pacific Northwest National Laboratory, Richland, WA, United States

*Corresponding Author

Pacific Northwest National Laboratory, 902 Battelle Boulevard, P.O. Box 999, MSIN P7-25, Richland, WA 99352 USA

Tel: $509-375-5055$

philip.schonewill@pnnl.gov

\begin{abstract}
The long-time ( $>100$ hours of operation) flux was measured for a set of five tests where nuclear waste slurry simulant was separated and continuously recycled using a stainless steel crossflow filter. The tests were conducted
\end{abstract}

Page 1 of 1 
at various constant axial velocities and transmembrane pressures. In all five tests, the filter flux continued to decay at long times and did not reach a steady-state value. The long-time slope of the flux decay was unaffected by the axial velocity, but a larger transmembrane pressure resulted in a larger slope. Post-test examination of the filter did not show evidence of significant depth fouling. The experimental results are compared to theoretical predictions of the time to initiate cake formation and the time to reach steady-state predicted by models from the literature, both of which do not imply long-time phenomena would be expected. A more reasonable match between theory and experiment was achieved using a model based on the principles of dead-end filtration.

Keywords: crossflow filtration; filter fouling; solid-liquid separations; backpulsing

\section{Introduction}

Approximately 60,000 metric tons of high-level waste sludge is currently contained in 177 underground storage tanks at the Hanford Nuclear Reservation near Richland, Washington. The sludge is to be vitrified into a glass in the Hanford Tank Waste Treatment and Immobilization Plant (WTP), which is currently under construction. Before the waste is vitrified, some of the waste will be pre-treated to reduce the volume of highly radioactive material, i.e., high level waste (HLW) that will be processed by removing species that limit the loading of HLW in glass. Crossflow filtration, specifically microfiltration, is one of the principal separation technologies that will be implemented as a part of the pre-treatment process.

Crossflow filters will be used to process waste slurries that contain colloidal particles, non-colloidal $(>1 \mu \mathrm{m})$ particles, and dissolved solutes. Crossflow filtration has been widely used in many different industries as a separation technique, such as wastewater treatment and food processing (Ripperger and Altmann, 2002). The crossflow geometry was selected for nuclear waste treatment because, ideally, it minimizes build-up of solid particles and limits fouling. It has been demonstrated to be an effective separation 
technique for radioactive waste slurries (Mann and Todd, 2000; Nash et al., 2003) or non-radioactive waste simulants designed to mimic actual (i.e., radioactive) waste (Russell et al., 2009a, Billing et al., 2009, Daniel et al., 2009, 2010). However, it is expected that sustaining waste filtration operations will be challenged by fouling of the filter elements during high-level waste (HLW) treatment operations. Specifically, the fouling dynamics of the crossflow filters planned for use to process HLW at the Hanford site are still not completely understood.

This lack of understanding derives from the complex nature of the waste feeds, with waste feeds for each tank (or small tank groupings) typically having a unique chemical composition and physical properties. Even for a given waste storage tank, the waste feed is heterogeneous in both chemical constituents (which include insoluble mineral phases, precipitated salts, and dissolved species in concentrations ranging from 1 to 10 mol/L) and particle size ( $\square 0.2 \mu \mathrm{m}$ to $300 \mu \mathrm{m})$. In addition, the waste feed will be subjected to numerous processes (including as-received dewatering, dewatered feed caustic leaching, post-leach washing, etc.), that fundamentally alters waste chemistry and particle size, further complicating assessment of how the slurry in the filter evolves over the filtration time. 
Thus far, crossflow filtration experiments performed with actual HLW wastes or HLW simulants have been short (a maximum of 12 hours of undisturbed processing time) relative to the expected processing time (on the order of hundreds of hours). The lack of long-time data is an important issue to address. Crossflow filtration of HLW simulants has, thus far, not exhibited a steadystate behavior (on the 12 hour time scale) and showed decline in performance, e.g. measured permeate flux, after days of operation in a pilot scale facility (Daniel et al., 2010).

The primary objective of this work is to improve understanding of crossflow filtration performance with a well-characterized waste simulant. To this end, a series of bench-scale filtration tests were performed using a stainless steel microfilter and a waste simulant used in previous testing (Billing et al., 2009; Daniel et al., 2010), with transmembrane pressure (TMP) and axial velocity as testing variables. The test duration was chosen to be long enough to observe long-term filtration performance trends, e.g. on the order of 100 hours.

\section{Experimental}

The crossflow filtration experiments that are the subject of this work were conducted in a bench top system mounted on a skid that allowed up to $25 \mathrm{~L}$ of a solution to be circulated through the crossflow filter. A schematic of the test skid, referred to as the cell unit filter (CUF), is shown in Figure 1. The skid used a data acquisition and collection system to measure filter feed flow rates, filtrate flow rates, system pressures, and temperatures simultaneously. The slurry in the reservoir was fed through the slurry circulation loop using a stainless steel progressive cavity rotary lobe pump (Johnson Sterilobe pump, model SLAL). The rotary lobe pump was driven by a $3 \mathrm{HP}$ motor with a 300 to $1264 \mathrm{rpm}$ operating range that was capable of producing a maximum flow of approximately $55 \mathrm{~L} / \mathrm{min}[15 \mathrm{gpm}]$. A heat exchanger on the circulation flow loop was used to cool the feed solution (remove pump heat) during filtration operations. Control of the transmembrane pressure was refined by setting a pinch valve (V4) downstream of the crossflow filter. Permeate from the filter passes through a mass flow meter and can be either returned to 
the feed reservoir or collected in another vessel. The system is capable of applying backpulses to the crossflow filter, during which a chamber is filled up with $\sim 0.25 \mathrm{~L}$ of filtrate and then forced back through the filter pores using compressed gas at a pressure of up to $0.55 \mathrm{MPa}$ [80 psig].

In the following sections, additional details about the experiments are elucidated. First, the filter media that was studied is described in more detail. Second, the composition and physical properties of the waste simulant that was filtered are specified. Finally, the procedure used to perform the tests is summarized.

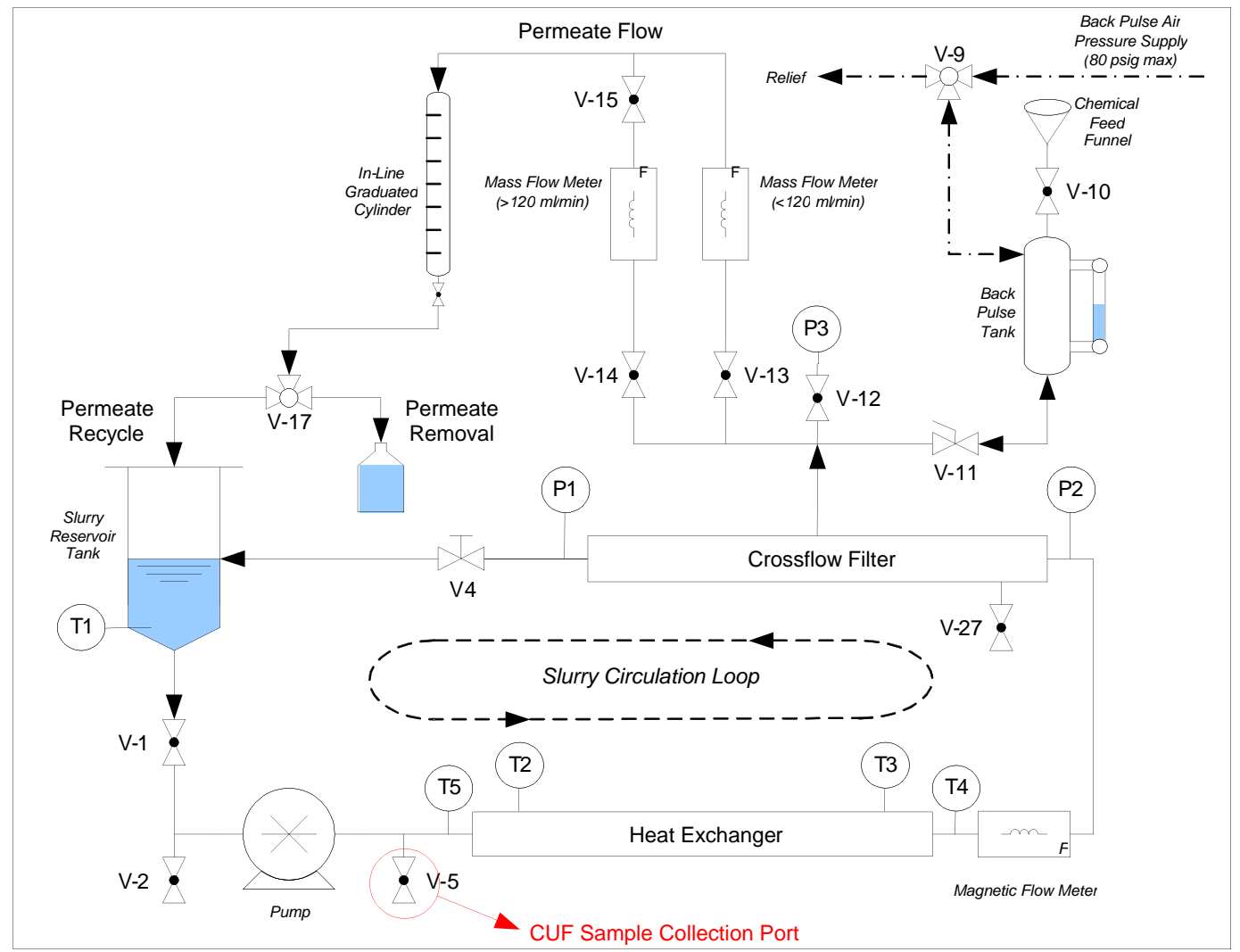

Figure 1. Schematic of the CUF test skid. 


\subsection{Filter Media}

The crossflow filter tested was a 316 stainless steel symmetric element with a $1.27 \mathrm{~cm}$ [0.5 in] inside diameter supplied from the Mott Corporation (Farmington, CT). Mott specifies the filter grade as $0.1 \mu \mathrm{m}$. This filter is of the same grade and diameter as the tubes that are planned to be used to filter waste at the WTP, with the exception of being shorter; it has a length, $L$, of $0.61 \mathrm{~m}$ [2 ft] instead of $3.05 \mathrm{~m}$ [10 ft] (see Figure 2). An SEM image of the filter cross-section, obtained by destructive evaluation after completion of the testing, is shown in Figure 3. This image illustrates both the distribution of pore size and the tortuosity of the filter media, which should allow it to retain submicron particles with high efficiency. Analysis of manufacturer data, including isopropanol bubble point, filter flux data and SEM images (Rubow and Jha, 1999), indicated that the Mott grade 0.1 sintered stainless steel filter elements have an effective hydrodynamic pore radius in the range of 1 to $3 \mu \mathrm{m} .{ }^{1}$ Thus, it was expected that the filter would not reject solid particles of sizes $0.1 \mu \mathrm{m}$ as the grade suggests, but may permit particles as large as $\sim 3 \mu \mathrm{m}$ to enter filter pores.
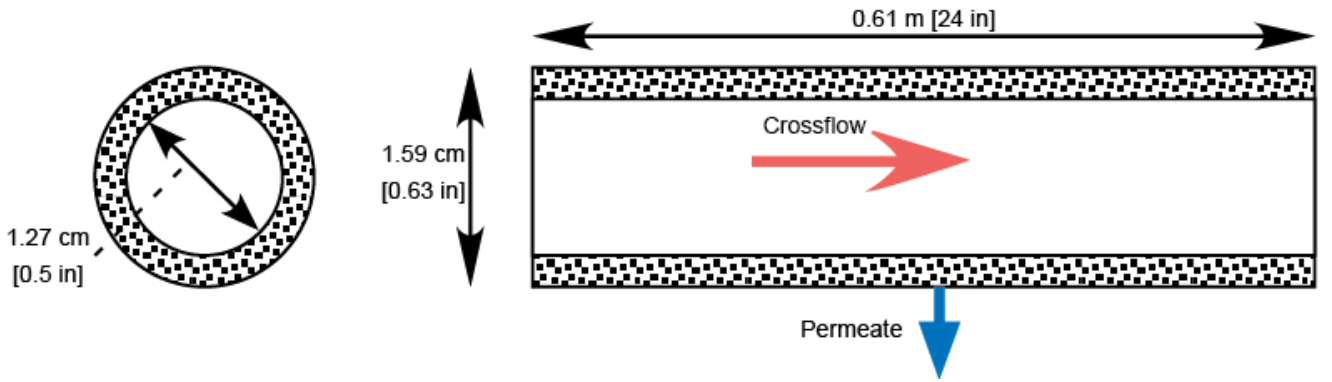

Figure 2. Representative schematic with dimensions of the filter element used in this work.

\footnotetext{
${ }^{1}$ Additional information available from manufacturer in: Owsiany M. 2007. "Mott HyPulse® LSX Data Summary - 24590-MOTT-FDP02.” Mott Corporation, Farmington, Connecticut.
} 


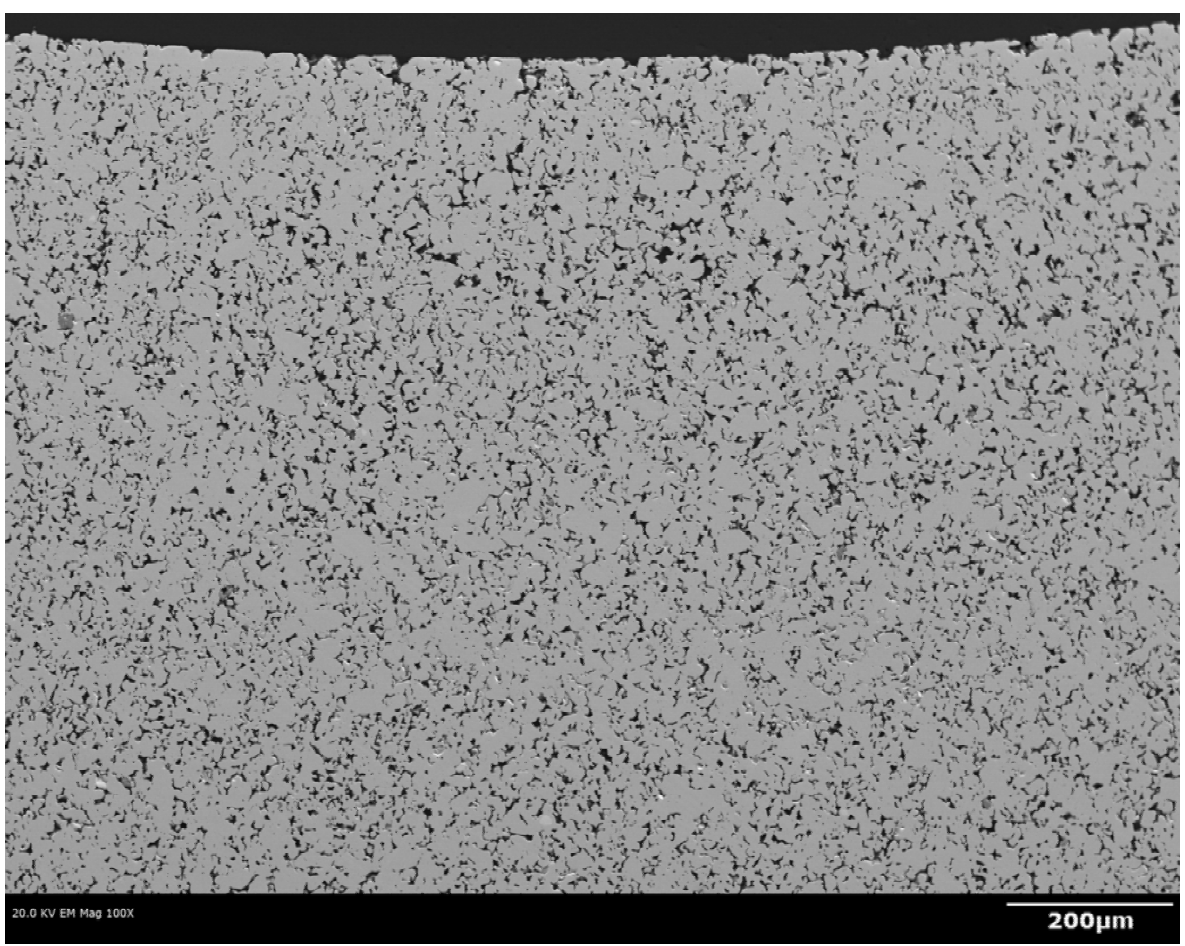

Figure 3. SEM Image of CUF Filter Element Cross-Section. The filter is oriented so that the inner surface is at the top of the image.

The filter elements were installed in a shell-and-tube configuration with an outer tube surrounding the filter element to capture the filtrate while the inlet and the outlet of the filter (which extend past the shell and provide access to the inside diameter of the filter) were welded to steel tubing of a matching outer/inner diameter. The shell side had two 3/8-inch stainless steel tubes exiting from the filter assembly, one in the center to collect filtrate from the filter, and the other near the inlet of the filter to function as a drain. Pressure ports ( $1 / 4$-inch stainless steel tubing) were installed on the inlet and outlet connections to the assembly to measure the pressure inside the filter. O-ring face seal (Swagelok VCO®) fittings purchased from the Swagelok Company (Solon, $\mathrm{OH}$ ) were also placed on the inlet and outlet filter feed tube connections for easy installation to the filtration/leaching skid. 


\subsection{Filtration Simulant}

The material being filtered in these experiments is a slurry that was designed to mimic nuclear waste found in the Hanford Tank farm that will be processed in the WTP. A similar simulant has been used in prior filtration testing (over a shorter duration) at the bench and pilot scale (Billing et al., 2009; Daniel et al., 2009; Daniel et al., 2010). For more detailed information on the simulant composition and makeup refer to Scheele et al., 2009, where the material used in these tests was from Batch 2 (see Tables 3.10, 3.12, and 3.13). The aqueous chemical concentrations used are typical of ranges expected for feed to the WTP but were not selected to represent the contents of any particular Hanford waste tank. The major solid components are gibbsite, boehmite, iron oxy-hydroxide, and sodium oxalate. The supernate contained various amounts of soluble ion pairs, primarily an anion paired with sodium (which is present at a concentration of approximately $5 \mathrm{~mol} / \mathrm{L}$ ), such as nitrate, nitrite, sulfate, phosphate, hydroxide, and oxalate.

The simulant was reconstituted and split into several separate "aliquots" of $\sim 10 \mathrm{~L}$. A new aliquot was used in each of the test. An aliquot's physical properties were reassessed prior to use in testing, as approximately 2 years had transpired between the production of the simulant and the experiments discussed in this work. The average physical properties of the slurry are given in Table 1, and the average before and after test particle size distributions (PSDs) are given in Figure 4. The PSDs shown in Figure 4 demonstrate that significant amounts of particles are smaller than the estimated hydrodynamic pore size $(1-3 \mu \mathrm{m})$. The pre-test and post-tests PSD in Figure 4 also show that pumping of the simulant in the CUF reduced particle size over the course of a test, most likely by disrupting particle agglomerates by shear. Thus, as the test progressed, the fraction of particles that were smaller than the hydrodynamic pore size increased. 
Table 1. Average physical properties of the waste simulant used in the experiments.

\begin{tabular}{|c|c|c|c|}
\hline Physical Property & Mean & $\begin{array}{l}\text { Error in } \\
\text { Mean }^{(a)}\end{array}$ & $\begin{array}{c}\text { Measurement } \\
\text { Variability }^{(b)}\end{array}$ \\
\hline \multicolumn{4}{|l|}{ Rheology: } \\
\hline Bingham Yield Stress, Pa & 0.06 & \pm 0.01 & \pm 0.04 \\
\hline Bingham Consistency, $\mathrm{mPa} s$ & 3.73 & \pm 0.03 & \pm 0.12 \\
\hline Supernate Viscosity, $\mathrm{mPa} \mathrm{s}$ & 2.80 & \pm 0.03 & \pm 0.13 \\
\hline \multicolumn{4}{|l|}{ Density: } \\
\hline Slurry Density, kg L ${ }^{-1}$ & 1.283 & \pm 0.002 & \pm 0.010 \\
\hline Supernate Density, $\mathrm{kg} \mathrm{L}^{-1}$ & 1.2321 & \pm 0.0005 & \pm 0.0030 \\
\hline \multicolumn{4}{|l|}{ Solids Concentrations: } \\
\hline Total Solids, wt\% & 31.1 & \pm 0.1 & \pm 0.9 \\
\hline Undissolved Solids, wt $\%$ & 6.3 & \pm 0.2 & \pm 1.1 \\
\hline Supernate Dissolved Solids, wt $\%$ & 26.5 & \pm 0.1 & \pm 0.4 \\
\hline \multicolumn{4}{|l|}{ Particle Size Percentile: } \\
\hline $\mathrm{d} 10, \mu \mathrm{m}$ (before test/after test) & $1.42 / 0.82$ & $\pm 0.04 / 0.06$ & $\pm 0.07 / 0.13$ \\
\hline $\mathrm{d} 50, \mu \mathrm{m}$ (before test/after test) & $6.7 / 3.2$ & $\pm 0.5 / 0.4$ & $\pm 0.8 / 0.8$ \\
\hline $\mathrm{d} 90, \mu \mathrm{m}$ (before test/after test) & $24 / 12$ & $\pm 2 / 1$ & $\pm 3 / 2$ \\
\hline
\end{tabular}

(a) The error in the mean is calculated as $z_{95} \sigma / \sqrt{N}$, where $z_{95}$ is 1.96 (95\% confidence limit multiplier), $\sigma$ is the sample standard deviation, and $N$ is the number of measurements used to compute the mean. $N$ was greater than 30 for all measurements except rheology, which had $N$ of 20 or greater.

(b) The measurement variability is computed as ${Z_{95}}_{9} \pi$, and represents the expected range of measurement variation for any given sample. With exception of rheology measurements, $N$ was greater than 30 for all measurements except rheology, which had $N$ of 20 or greater.

As mentioned, a new portion of simulant was used after the preceding test was completed and the filter had been thoroughly cleaned. Thus, each test was similar in the respect that the starting material had not been previously processed in the CUF and had aged for approximately 2 years. The testing occurred over the course of a few months, but previous examination of aging effects 
on this simulant concluded that only minor changes in PSD, rheology, and chemical speciation occur over comparable time periods (Russell et al., 2009b). This was confirmed by measuring the properties of the simulant portions used in each test. Because the measured properties for the five simulant portions were very similar (essentially uniform), the properties given in Table 1 and Figure 4 are representative of the simulant for all of the testing.

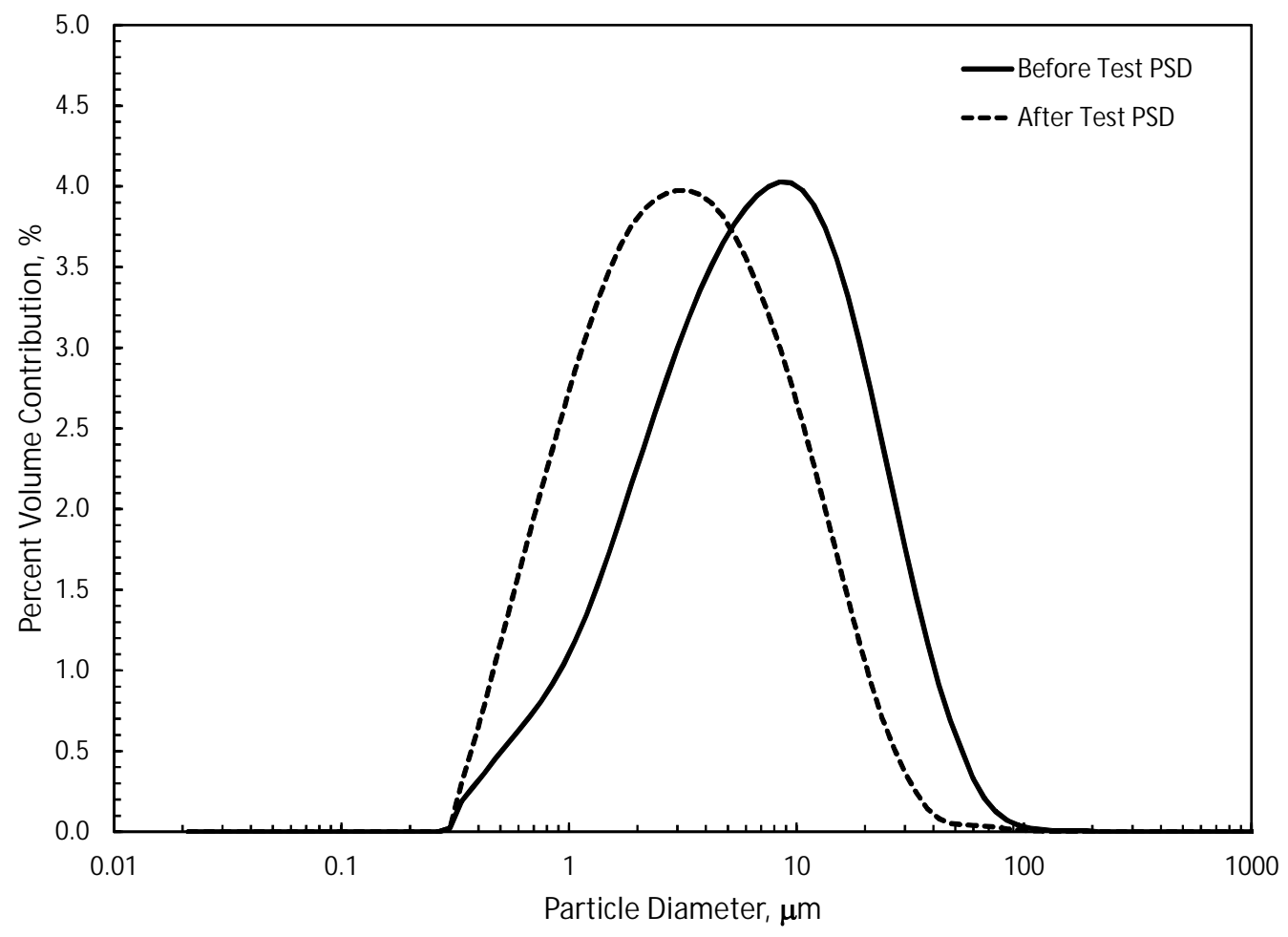

Figure 4. Average of the particle size distribution of the waste simulant both before a test (solid line) and after a test (dashed line).

\subsection{Experimental Approach}

As is evident from examination of the filtration simulant PSD in Figure 4, there is a significant fraction of particles in the slurry that are smaller than the hydrodynamic pore size.

Consequently, solids were expected to penetrate into the filter pores during testing. Because the choice of filter media is fixed for its intended application (treating nuclear waste), it was crucial 
to assess how severely particulate penetration (i.e., fouling) affects long-term filter performance. The presence of amorphous solid components, e.g. iron oxyhydroxide among others, adds an additional layer of complexity. Precisely how all the different solid components interact during filtration in a slurry with a $5 \mathrm{~mol} / \mathrm{L} \mathrm{Na}^{+}$supernate was difficult to predict a priori. Thus, collecting some long-time performance data as a function of operating parameters was performed to study the problem empirically.

To that end, five long-time filtration tests were conducted over a range of $\Delta P_{\text {nom }}$ and $U_{\text {nom }} . U_{\text {nom }}$ is the nominal area-average slurry velocity in the crossflow filter, calculated as follows:

$$
U_{n o m}=\frac{4 Q_{s}}{\pi D^{2}}
$$

where $Q_{s}$ is the slurry volumetric flow rate and $D$ is the inner diameter of the filter. Table 2 shows the matrix of nominal operating conditions that were used for the tests. The baseline test is $\mathrm{S} 1 \mathrm{~T} 1$, conducted at a $\Delta P_{n o m}$ of $275.8 \mathrm{kPa}(40 \mathrm{psid})$ and $U_{n o m}$ of $4.57 \mathrm{~m} / \mathrm{s}(15 \mathrm{ft} / \mathrm{s})$. The $\mathrm{S} 1 \mathrm{~T} 1$ conditions have been tested in the same CUF previously for shorter periods, e.g. continuous durations of up to 12 hours (Daniel et al., 2011). All filtration testing was conducted at $25 \pm 5^{\circ} \mathrm{C}$ using different portions of the same batch of waste simulant as described previously. The Reynolds number $(R e)$, defined on the basis of the slurry properties $\rho$ (density) and $\mu$ (viscosity), is also provided in the table. Note that in place of the viscosity, the Bingham consistency of the slurry was used; rheology measurements of the slurry determined it was effectively a Newtonian fluid as it had a near-zero Bingham yield stress. The magnitude of the Reynolds numbers indicates that the flow in all five tests was fully turbulent in the crossflow filter tube. 
Table 2. Long-Time Testing: Nominal Operating Conditions

\begin{tabular}{|c|c|c|c|}
\hline $\begin{array}{c}\text { Test No. } \\
\text { (identifier) }\end{array}$ & $\begin{array}{c}\Delta \boldsymbol{P}_{\text {nom }}(\mathbf{k P a} \\
\text { [psid] })\end{array}$ & $\boldsymbol{U}_{\text {nom }}(\mathbf{m} / \mathbf{s}[\mathbf{f t} / \mathbf{s}])$ & $\boldsymbol{R} \boldsymbol{e}\left(\rho \boldsymbol{U}_{\text {nom }} \boldsymbol{D} / \boldsymbol{\mu}\right)$ \\
\hline 1 (S1T1) & $275.8[40]$ & $4.57[15]$ & $2.00 \times 10^{4}$ \\
\hline 2 (S1T2) & $275.8[40]$ & $5.18[17]$ & $2.26 \times 10^{4}$ \\
\hline 3 (S1T3) & $275.8[40]$ & $3.96[13]$ & $1.73 \times 10^{4}$ \\
\hline 4 (S1T4) & $413.7[60]$ & $4.57[15]$ & $2.00 \times 10^{4}$ \\
\hline 5 (S1T5) & $137.9[20]$ & $4.57[15]$ & $2.00 \times 10^{4}$ \\
\hline
\end{tabular}

Each test was conducted in four parts. The first part established the pre-test state (initial resistance) of the filter by measuring the clean water flux using $0.01 \mathrm{M} \mathrm{NaOH}$ at varying TMP. After the filter pre-test state was measured, the CUF was drained and then $\sim 6.2 \mathrm{~L}$ of the waste simulant (varied slightly depending on the solids content) was loaded into the slurry reservoir tank. This volume of slurry was selected to match the solids loading used in other testing, which was $0.14 \mathrm{~kg}$ undissolved solids (UDS) in the slurry per square meter of filtration surface area [e.g. $1.5 \mathrm{~kg} \mathrm{UDS} / \mathrm{ft}^{2}$ ]. The ratio of UDS to filter area was held constant in order to have a similar particle inventory in all the tests. In the second part of the test, the CUF was operated in recycle mode continuously for a minimum of 100 hours. In recycle mode, all the permeate is continuously returned to the feed reservoir and the undissolved solids concentration is approximately constant. No back pulses were performed during this part of the testing.

In the third part of the test, a series of six back pulses were performed over approximately one hour to establish the magnitude (if any) of the filter fouling that was reversible after the justconcluded 100 hour period of filtration. Following the backpulses, the CUF was operated in recycle mode for a period of approximately four hours. Finally, the post-test filter condition was established by performing clean water flux testing. The CUF was drained and cleaned using $0.5 \mathrm{M}$ oxalic acid and $0.01 \mathrm{M} \mathrm{NaOH}$ after each of the first four tests to remove any fouling 
particles that were left behind. After the fifth test, only a wash with $0.01 \mathrm{M} \mathrm{NaOH}$ was performed so that a post-test destructive examination of the filter could be conducted.

\section{Results and Discussion}

The primary quantity of interest during crossflow filtration testing is the permeate production rate, i.e., the filter flux. Since, as mentioned previously, the CUF was operated in recycle mode, the slurry solids concentration was approximately constant and the filter flux was only expected to change with time. The flux will be the focus of the discussion and analysis. Other test data, namely time series of process variables such as temperature, pressure, and flow rate were also measured, but no anomalous trends or behavior were observed. All the flux data presented in this section and discussed throughout have been normalized by TMP and temperature using the following expression:

$$
J_{25, \mathrm{TMP}}=\left(\frac{\Delta P_{n o m}}{\Delta P}\right) \frac{Q e^{\left(2500\left(\frac{1}{T}-\frac{1}{298.15}\right)\right)}}{A_{F}} .
$$

In Equation (1), $Q$ is the unadjusted permeate flow rate, $T$ is the absolute temperature (in Kelvin), $A_{F}$ is the filter area $(\pi D L)$, and $\Delta P$ and $\Delta P_{\text {nom }}$ are the measured and nominal (target) TMP, respectively. The correction to the flow rate described by the exponential term was first reported in Geeting and Hallen (Geeting and Hallen, 2005). The correction is an Andrade correlation that adjusts for viscosity and surface tension changes when the temperature is different from $25^{\circ} \mathrm{C}$. The measured transmembrane pressure is determined by

$$
\Delta P=\frac{P_{\text {inlet }}+P_{\text {outlet }}}{2}-P_{\text {permeate }}
$$

where $P_{\text {inlet }}$ is the pressure at the filter inlet, $P_{\text {outlet }}$ is the pressure at the filter outlet, and $P_{\text {permeate }}$ is the pressure on the permeate side of the filter. It is worth pointing out that 
Equation (1) cannot be strictly applied if, as expected, the cake is compressible. Filter cakes have been demonstrated to form irreversibly for a variety of particles sizes and types, e.g. $\mathrm{CaCO}_{3}$ slurries (Benkahla et al., 1995), activated sludge (Defrance and Jaffrin, 1999), silica particles (Huisman et al., 1998), and heterogeneous protein mixtures (Ye and Chen, 2005). However, in these experiments, the actual TMP rarely deviated significantly from the nominal TMP, so the corrections are made to smooth out the small deviations (less than $7 \mathrm{kPa}(1 \mathrm{psid}))$ and oscillations in the flux data arising from fluctuations in the TMP signal.

The subscripts 25 and TMP indicate that the flux has been normalized to a temperature of $25^{\circ} \mathrm{C}$ and the nominal TMP of the test $(137.9,275.8$ or $413.7 \mathrm{kPa}$, respectively). For the remainder of this manuscript, the normalized flux will be referred to simply as $J_{t}$ or $J_{b p, t}$, where $t$ refers to elapsed time, e.g. $t=0$ for the initial value, etc. and the subscript $b p$ refers to fluxes obtained after backpulsing was performed. Note that the instrument outputs from the CUF are averaged into one-minute segments for data analysis, so transient behavior with timescales smaller than one-minute are not resolved. ${ }^{2}$ Another possible consequence of one-minute averaging is the inclusion of spurious data points, as one spike (either an unexpectedly large increase or decrease in the value of the permeate flow rate) can distort the average value. Some spikes were observed, in particular at tests with higher TMP and axial velocity. Since these spikes were not associated with any changes in operating conditions, vibration or electrical interference was suspected as the cause. The spikes were considered unrepresentative of actual filtration behavior and were removed from the data set using Dixon's Q-Test at the 80\% confidence level (Rorabacher, 1991).

\footnotetext{
${ }^{2}$ Transient behavior on this scale is only expected during backpulsing events. The averaged data is derived from measurements occurring every 2.5 seconds; thus, each one-minute average contains 24 measurements.
} 


\subsection{Filter Flux Data}

The flux evolution over the $~ 100$-hour operating period is compared for the constant TMP tests (S1T1, S1T2, and S1T3) in Figure 5. For these and other similar figures, the data is shown as lines (for clarity) due to the large number of data points. In all three cases, the decay in the flux rate is initially rapid before decreasing with a constant slope at longer times. At long times the data for all three constant TMP tests is decaying at the same rate (or nearly so, as the data points appear parallel), indicating that axial velocity, over the range tested, has little to no effect on how filtration behavior changes in the limit of long times. The results also imply that axial velocity does affect the absolute long time value of the flux by shifting the value of the initial flux, where higher velocities result in higher initial fluxes i.e., S1T2 flux $>$ S1T1 flux $>$ S1T3 flux. This is not surprising because the flow is fully turbulent in all three cases. Expanding the velocity range to include lower velocities near the range where laminar-turbulent transition occurs may lead to different functionality, and may be the subject of future study. 


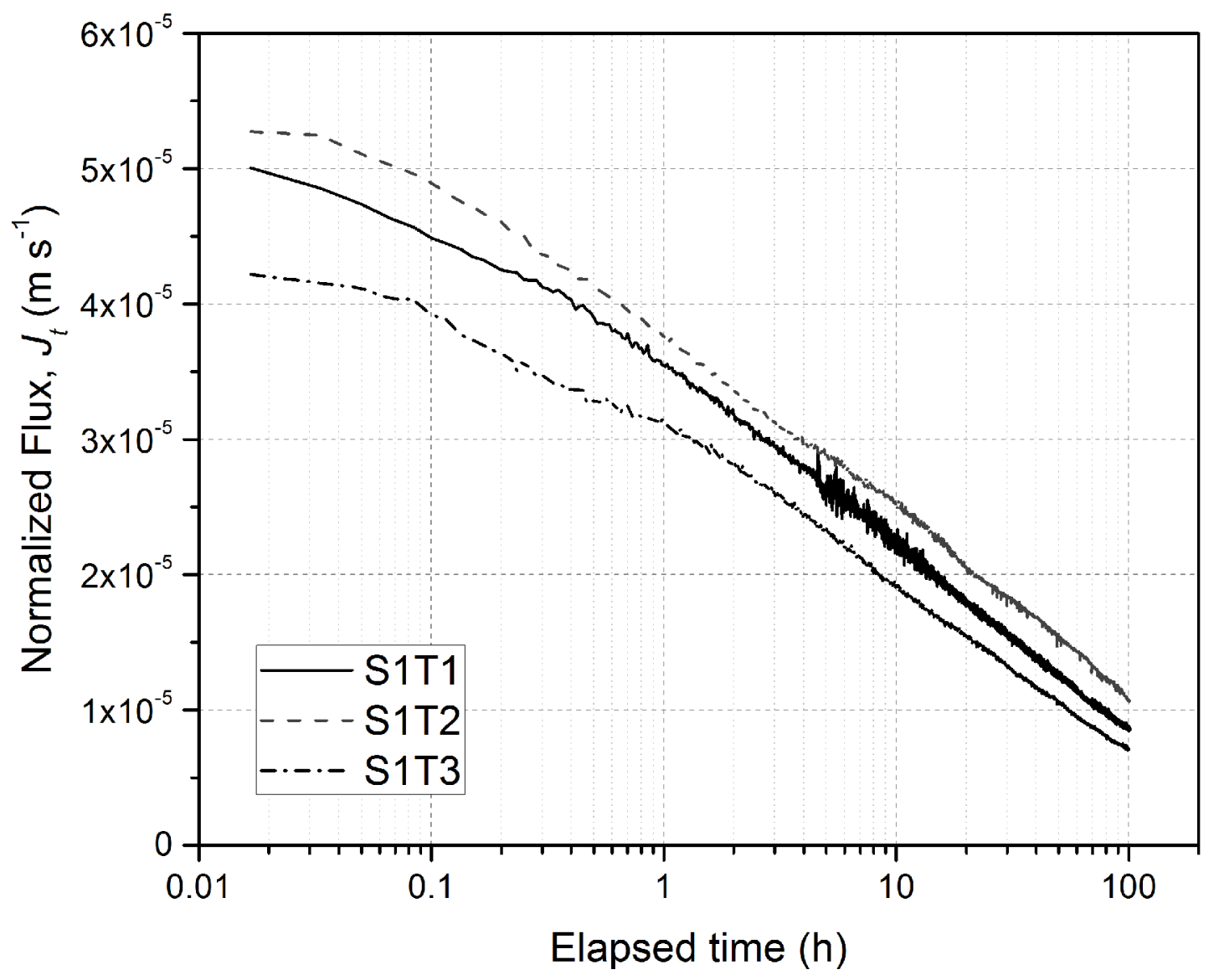

Figure 5. Normalized flux $\left(J_{t}\right)$ versus elapsed time for the constant TMP $(275.8 \mathrm{kPa})$ tests. The nominal axial velocities were as follows: S1T1 $=4.57 \mathrm{~m} / \mathrm{s}, \mathrm{S} 1 \mathrm{~T} 2=5.18 \mathrm{~m} / \mathrm{s}$, and S1T3 $=3.96$ $\mathrm{m} / \mathrm{s}$.

A similar comparison is made for the constant axial velocity tests (S1T1, S1T4, and S1T5) in Figure 6. Again, the decay in the flux rate is initially rapid and then decreases with a constant slope at longer times. In this case, TMP appears to affect the magnitude of the slope at long times. Thus, even though S1T5 (TMP = 20 psid) starts at a much lower initial flux, by the end of the test it has the highest flux; the opposite is true of S1T4 (TMP $=60$ psid). An increasing decline in flux with increasing TMP suggests that the fouling mechanism(s) are influenced 
strongly by the applied pressure, due to the pressure forcing a greater number of particles to interact with the filter media and cake as the slurry travels down the filter tube.

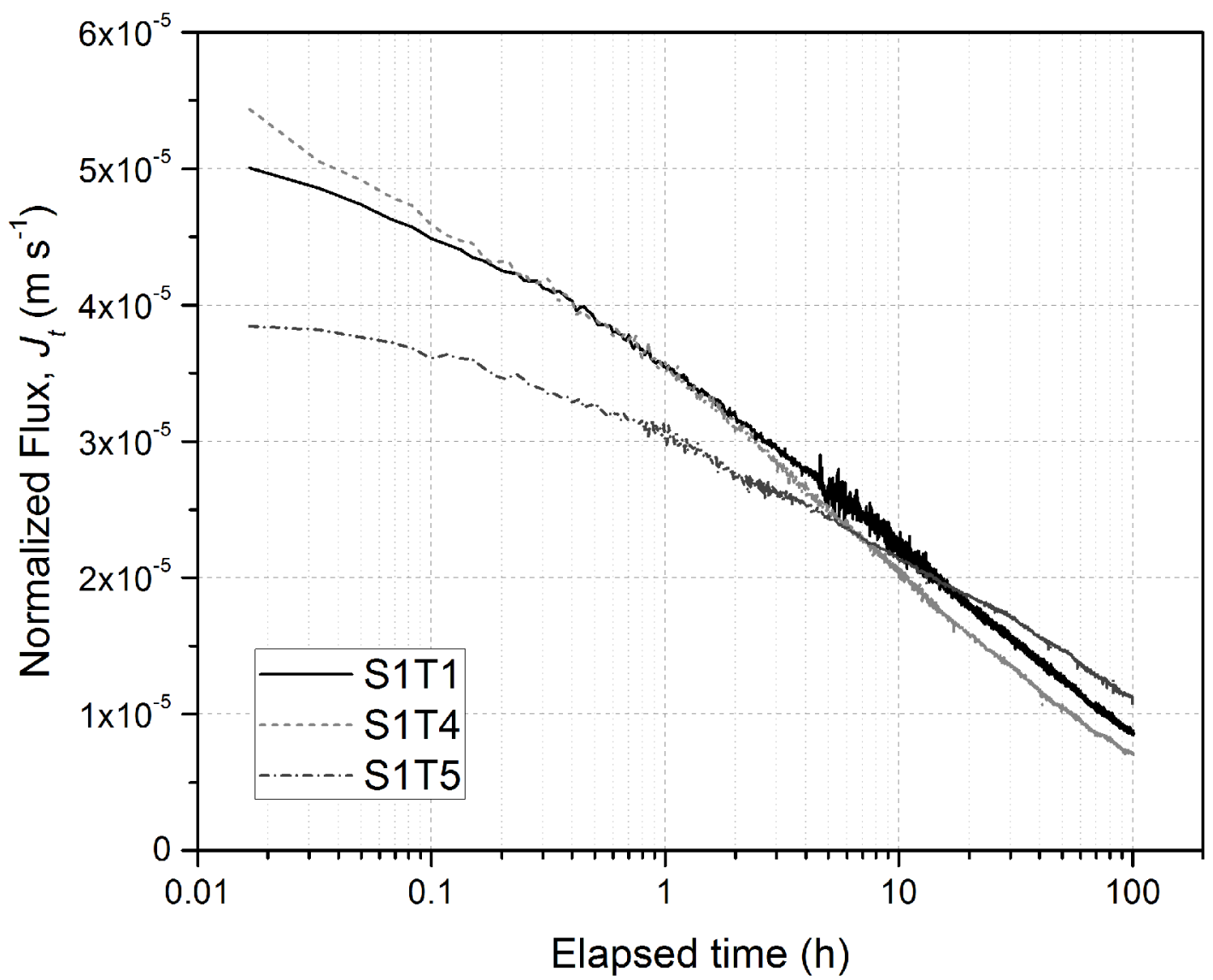

Figure 6. Normalized flux $\left(J_{t}\right)$ versus elapsed time for the constant axial velocity $(4.57 \mathrm{~m} / \mathrm{s})$ tests. The nominal transmembrane pressures were as follows: S1T1 $=275.8 \mathrm{kPa}, \mathrm{S} 1 \mathrm{~T} 4=413.7$ $\mathrm{kPa}$, and $\mathrm{S} 1 \mathrm{~T} 5=137.9 \mathrm{kPa}$. 


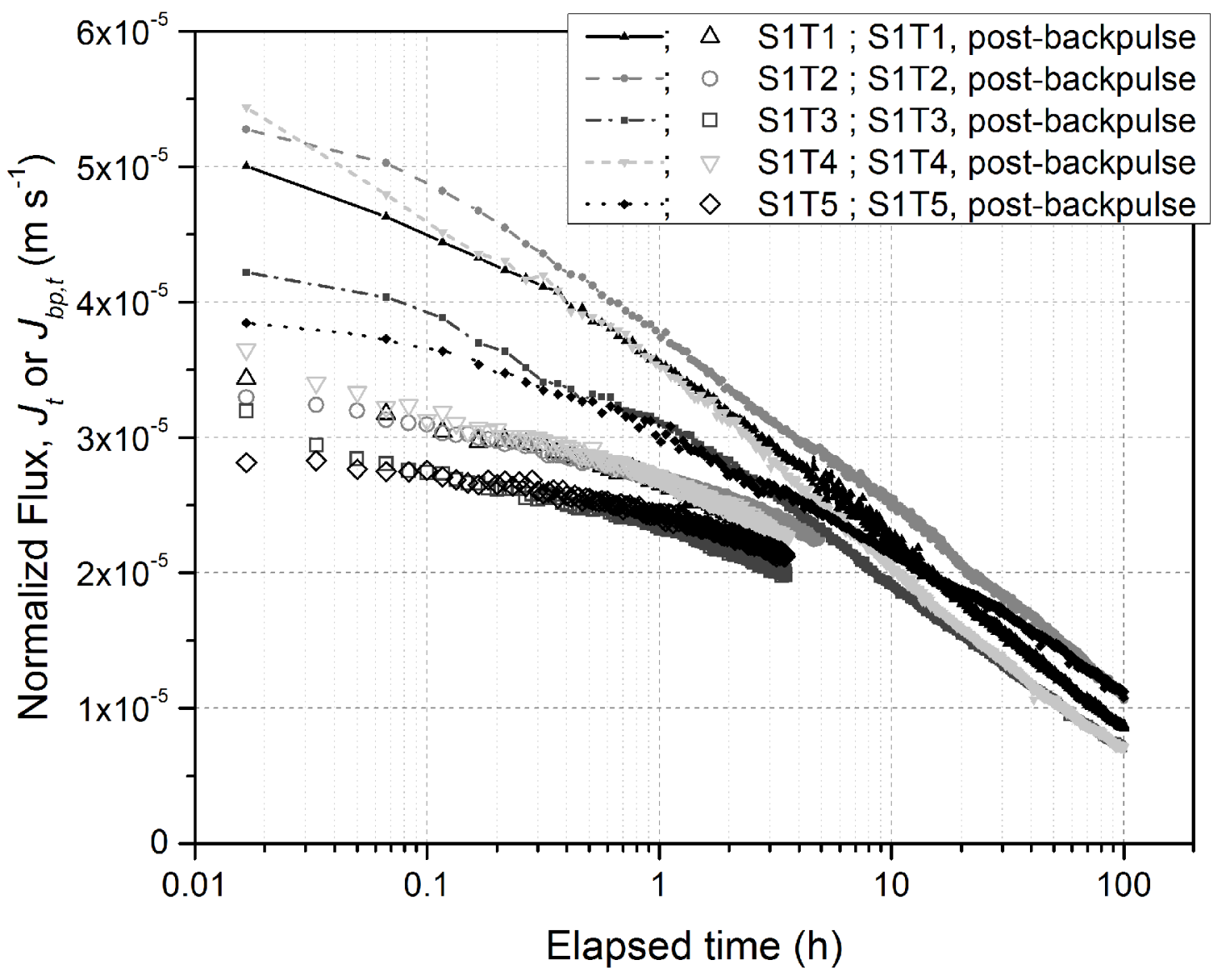

Figure 7. Normalized flux $\left(J_{t}\right)$ versus elapsed time for the all Series 1 tests. The elapsed time was reset after the backpulses for ease of comparison with the 100 hour data. The test conditions were as follows $\left(\Delta \mathrm{P}_{\text {nom }}(\mathrm{kPa}) / \mathrm{U}_{\text {nom }}(\mathrm{m} / \mathrm{s})\right)$ : $\mathrm{S} 1 \mathrm{~T} 1=275.8 / 4.57, \mathrm{~S} 1 \mathrm{~T} 2=275.8 / 5.18, \mathrm{~S} 1 \mathrm{~T} 3=$ 275.8/3.96, S1T4 = 413.7/4.57, and S1T5 = 137.9/4.57.

In Figure 7, all five tests are shown, together with the flux measured after the backpulsing was performed. Note that the elapsed time was reset to zero after the backpulsing for convenience. For all the tests, the initial flux after backpulsing $\left(J_{b p, 0}\right)$ was $60-70 \%$ of the initial flux before backpulsing $\left(J_{0}\right)$. This $30-40 \%$ reduction in flux was irreversible and could not be completely recovered without chemical cleaning of the filter. 


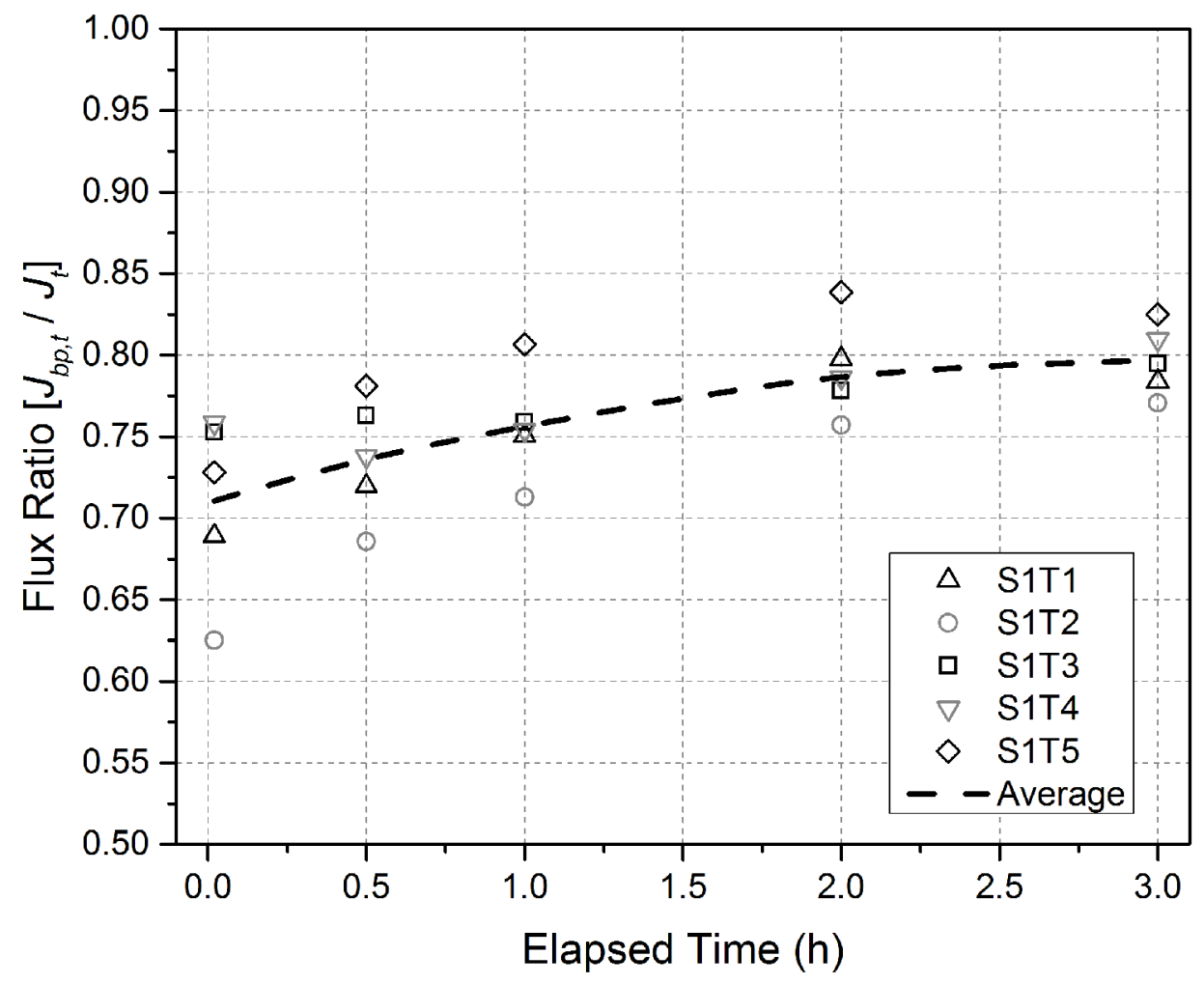

Figure 8. The ratio of the flux measured after 100 hours of operation and 6 backpulses $\left(J_{b p, t}\right)$ to the flux measured initially in the filter $\left(J_{t}\right)$ at the same discrete elapsed times. Elapsed time is zero when the $6^{\text {th }}$ backpulse was complete and the target conditions were first achieved, respectively. The dotted line shows the average of the 5 data sets.

There is evidence from the data of the five tests that irreversible fouling mechanism(s) impart a finite amount of flux degradation and cannot occur ad infinitum. The evidence is presented in Figure 8. Figure 8 shows the ratio of the post-backpulse flux $\left(J_{b p, t}\right)$ to the flux $\left(J_{t}\right)$ for all five Series 1 tests at discrete times from 0 to $3 \mathrm{~h}$ elapsed time. The ratio was calculated by comparing flux measurements at the same elapsed time. The elapsed time for the initial flux begins when the target conditions are reached. The elapsed time for the post-backpulse flux begins when the $6^{\text {th }}$ backpulse has been completed. At elapsed times near zero $(0.02 \mathrm{~h})$, a $25-40 \%$ reduction in flux is observed. After this point, the ratio increases with elapsed time, meaning that the post- 
backpulse fouling (or reduction in flux) is occurring at a slower rate than the fouling at the start of the 100-hour tests. Assuming that the magnitude of any reversible fouling that occurs is similar between the two filtration periods, the capacity of the filter to irreversibly foul had decreased. If only a finite amount of irreversible fouling can occur, the filter was likely fouled by consumption of pore volume or surface area that restricts permeate removal. The capacity to foul would decrease if there were a significant reduction in pore volume, the amount of appropriately sized particles, or both.

To investigate whether significant build-up of solids in the filter porous matrix had occurred over the course of a 100-h test, the filter media was destructively examined after the fifth test was completed. The media was cut into sections and examined on the inside and outside surfaces using both optical and scanning electron microscopes (SEM). The SEM was also used to examine two cross-sections of the filter from near the outlet end of the filter tube, using both secondary electron imaging (SEI) and back-scattered electrons (BSE). An example of the images collected is given in Figure 9 (top two images). The results of energy dispersive spectroscopy (EDS) for the elements oxygen, silicon, and aluminum (representative of simulant components) are also shown in the Figure 9, and the amounts that are present are concentrated near the inside surface of the filter tube (the top of each image). This suggests that very little solid particulate was present past a depth of 20 to 30 microns in the filter.

Recall that the same filter element was used for the five $\sim 100$-h tests, but was cleaned after each test until a baseline clean water flux of at least $7 \times 10^{-4} \mathrm{~m} \mathrm{~s}^{-1}$ was obtained (more than an order of magnitude greater than the starting flux in the experiments). Recovering a similar baseline clean water flux implies that the filter was in a very similar state before each test began. Thus, though the lack of appreciable material throughout the filter cross-section is due to the fifth test only, it is likely representative of the other four tests. The optical images of the filter inside surface showed some reddish-brown residue (which was not seen on the outside surface) that is typically indicative of the iron-containing compounds in the simulant. Presumably, these are the surface foulants that were removed during the filter cleaning process. However, it was difficult to 
collect additional quantitative information due to the stainless steel background of the filter media itself.

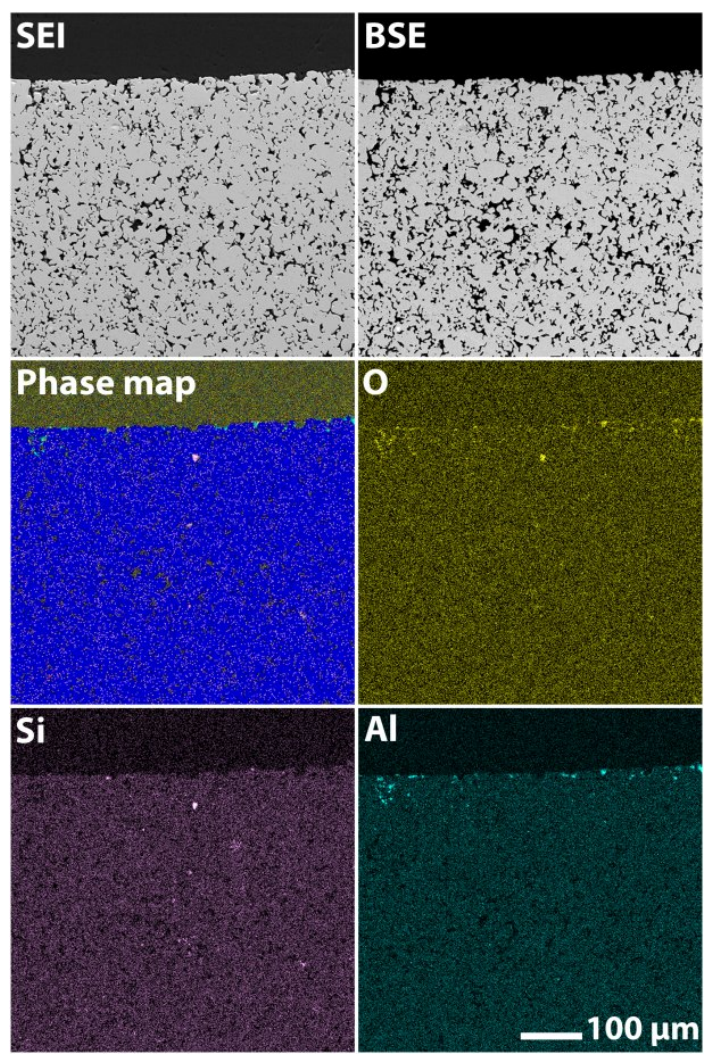

Figure 9. Images of the filter cross-section after testing obtained using a scanning electron microscope, with elemental analyses performed using EDS. The top of each image is the inside edge of the filter.

The most notable observation from the filtration data is that the flux does not appear to be approaching a steady-state value. It decays at more or less a constant rate (on a log-linear scale) from approximately $t=5 \mathrm{~h}$ until the filter is backpulsed at 100 hours. The post-backpulse data indicates that there is a portion of the flux which is recovered (reversible fouling) when the pores are perturbed and there is a portion that is not (irreversible fouling). Based on the test data, the irreversible portion appeared to be less significant than the reversible portion; this is supported by the lack of solid particles found in the filter interior during the destructive evaluation 
conducted after the fifth test. The reversible fouling is almost certainly due to the presence of a filter cake, and it would stand to reason that this is the mechanism that controls long-term filter flux. Thus, it can be postulated that the lack of an approach to steady-state suggests that the cake has not achieved a steady-state in the filter after 100 hours; rather, the cake was still evolving by growing in thickness, migration of smaller particles into interstitial spaces, compaction, or a combination thereof. The lack of a steady-state flux despite steady and well-controlled operating conditions illustrates the challenge of predicting crossflow filtration performance with the unique filter/slurry combinations that are typical of expected wastes.

\subsection{Comparison with Model Predictions}

The majority of models developed to describe the flux response of crossflow filtration models predict that a steady-state flux should be achieved during constant pressure filtration (for instance, refer to the recent review of Kim and DiGiano (Kim and DiGiano, 2009)). The physical explanation is that the fouling (or cake) build-up is limited via back transport induced by the crossflow. Eventually these competing effects come into balance and a steady-state flux is achieved. Yet a steady-state was not achieved in these tests despite large axial velocities and fully turbulent flow in the filter, which should supply a significant back transport or resuspension driving force for the solid particles. In fact, extrapolating forward in time using the last 50 hours of data, it would be expected that the flux would be $<1 \%$ of its starting value somewhere between 355 (S1T4) and 774 (S1T5) hours.

The expectation that a steady-state flux would be achieved is supported by several theoretical and experimental studies with crossflow filters (see for example Blake et al., 1992, Chang et al., 1995, Hwang et al., 1996, Zhang and Song, 2000, Hasan et al., 2013, Nguyen et al., 2014). In some of the referenced studies, a constant permeate flux was obtained in an hour or less. Steadystate flux has also been observed when filtering for long time periods using non-tubular crossflow filters. For example, runs of $>100$ hours with a rotary microfilter used to process other waste simulants achieved a constant flux (Herman et al., 2011). In contrast, other 
experimentation with the CUF over a similarly long time period ( 450 hours) using a different waste simulant exhibited similar flux behavior as in this case, i.e. flux that was continuing to decline with operating time (Schonewill et al., 2012). An important question, then, is what causes the difference in long-time behavior for the crossflow filter studied in the CUF system?

In general, models (and experimental data collected to support them) are developed using idealized systems, such as monodisperse spherical particles in a laminar flow. They may not adequately capture all the phenomena that occur with a more complex system (such as a multicomponent polydisperse chemical simulant in a turbulent flow, as is the case here). As an initial step, the assumption that cake growth was occurring in the experiments was tested. Based on the expected particle transport mechanisms, such as those outlined in a model proposed by Sethi and Wiesner (Sethi and Wiesner, 1997), the time to begin forming a cake was estimated. The critical time required to establish growth in the cake layer is given by the expression

$$
t_{c r}=\frac{\left(\frac{\tau_{w 0} a_{p}^{2}}{\mu_{0} J_{m}} I_{11}+\frac{k T}{6 \pi \mu_{0} a_{p} J_{m}} I_{12}\right)}{\left(J_{m}-v_{l 0}\right) \phi_{b}}
$$

where $a_{p}$ is the particle radius, $\mu_{0}$ is the viscosity of the supernate (particle-free fluid), $J_{m}$ is the permeate flux in absence of the cake layer (membrane-limited only), $k$ is Boltzmann's constant, and $\phi_{b}$ is the bulk suspension particle volume fraction. The wall shear stress in the absence of cake $\left(\tau_{w 0}\right)$ and the lift velocity in the absence of cake $\left(v_{l 0}\right)$ are both defined in Sethi and Wiesner (Sethi and Wiesner, 1997). The component integrals $I_{11}$ and $I_{12}$ are evaluated using the following expressions:

$$
I_{11}=\int_{\phi_{b}}^{\phi_{w}} \frac{0.33 \phi^{2}\left(1+0.5 e^{8.8 \phi}\right)}{\left(1+\frac{1.5 \phi}{1-\phi / \phi_{c}}\right)^{2}} \frac{\left(\phi-\phi_{b}\right)}{\phi} d \phi
$$




$$
I_{12}=\int_{\phi_{b}}^{\phi_{w}} \frac{\left(\phi-\phi_{b}\right)}{\phi} d \phi
$$

where $\phi_{c}$ and $\phi_{w}$ are the maximum packing volume fraction of the filter cake and the particle volume fraction at the wall of the filter, respectively. The recommended value of $\phi_{c}$ is 0.58 for a monodisperse, spherical and nondeformable ensemble of particles. A polydisperse suspension such as the simulant used in this work will have $\phi_{c}>0.58$. For this calculation, the integrals were evaluated with $\phi_{c}=0.65$ and 0.75 .

Some of the calculated parameters used in the calculation are given in Table 3, along with the critical times estimated for the conditions of each test. Note that $J_{m}$ was taken to be the initial flux of each test $\left(J_{0}\right)$ and $a_{p}$ is the d50 particle size measured before the test (see Table 1$)$. The critical time to begin cake growth, regardless of the test parameters, is less than 2 minutes. Though it does not unilaterally prove that cake growth is dominating the filtration behavior, Eq. 4 suggests cake growth was beginning near the start of the filtration tests (as assumed). An observation of Sethi and Wiesner is that larger particles (defined as $>0.1 \mu \mathrm{m}$, which is true of essentially all particles in the simulant) form thick cakes and effectively reduce surface area when crossflow filtration is performed in a tubular geometry. If the cake growth did not stabilize during the 100-h tests, this may explain the continued drop in filter flux. However, given the fully turbulent nature of the fluid flow in the crossflow filter (Table 2), this is not considered a likely cause.

Table 3. Calculation of critical time for cake growth for the conditions of all five tests using Eq

4. (Sethi and Wiesner, 1997).

\begin{tabular}{|c|c|c|c|c|c|c|c|c|c|c|}
\hline \multirow[b]{2}{*}{ Quantity } & \multicolumn{2}{|c|}{ S1T1 } & \multicolumn{2}{|c|}{ S1T2 } & \multicolumn{2}{|c|}{ S1T3 } & \multicolumn{2}{|c|}{ S1T4 } & \multicolumn{2}{|c|}{ S1T5 } \\
\hline & $\begin{array}{l}\phi_{\mathrm{c}}= \\
0.65\end{array}$ & $\begin{array}{l}\phi_{\mathrm{c}}= \\
0.75\end{array}$ & $\begin{array}{l}\phi_{\mathrm{c}}= \\
0.65\end{array}$ & $\begin{array}{l}\phi_{\mathrm{c}}= \\
0.75\end{array}$ & $\begin{array}{l}\phi_{\mathrm{c}}= \\
0.65\end{array}$ & $\begin{array}{l}\phi_{\mathrm{c}}= \\
0.75\end{array}$ & $\begin{array}{l}\phi_{\mathrm{c}}= \\
0.65\end{array}$ & $\begin{array}{l}\phi_{\mathrm{c}}= \\
0.75\end{array}$ & $\begin{array}{l}\phi_{\mathrm{c}}= \\
0.65\end{array}$ & $\begin{array}{l}\phi_{\mathrm{c}}= \\
0.75\end{array}$ \\
\hline$U_{\text {nom }}[\mathrm{cm} / \mathrm{s}]$ & \multicolumn{2}{|c|}{457} & \multicolumn{2}{|c|}{518} & \multicolumn{2}{|c|}{396} & \multicolumn{2}{|c|}{457} & \multicolumn{2}{|c|}{457} \\
\hline$J_{m}\left(J_{0}\right)[\mathrm{cm} / \mathrm{s}]$ & \multicolumn{2}{|c|}{$5.35 \times 10^{-3}$} & \multicolumn{2}{|c|}{$5.58 \times 10^{-3}$} & \multicolumn{2}{|c|}{$4.31 \times 10^{-3}$} & \multicolumn{2}{|c|}{$6.29 \times 10^{-3}$} & \multicolumn{2}{|c|}{$3.88 \times 10^{-3}$} \\
\hline$\gamma_{0}[1 / \mathrm{s}]$ & \multicolumn{2}{|c|}{2880} & \multicolumn{2}{|c|}{3264} & \multicolumn{2}{|c|}{2496} & \multicolumn{2}{|c|}{2880} & \multicolumn{2}{|c|}{2880} \\
\hline $\mathrm{v}_{10}[\mathrm{~cm} / \mathrm{s}]$ & \multicolumn{2}{|c|}{$5.14 \times 10^{-4}$} & \multicolumn{2}{|c|}{$6.61 \times 10^{-4}$} & \multicolumn{2}{|c|}{$3.86 \times 10^{-4}$} & \multicolumn{2}{|c|}{$5.14 \times 10^{-4}$} & \multicolumn{2}{|c|}{$5.14 \times 10^{-4}$} \\
\hline
\end{tabular}




\begin{tabular}{|c|c|c|c|c|c|c|c|c|c|c|}
\hline$\tau_{\mathrm{w} 0}\left[\mathrm{~g} / \mathrm{cm} \mathrm{s}^{2}\right]$ & 86.9 & 86.8 & 98.4 & 98.4 & 75.3 & 75.2 & 86.9 & 86.8 & 86.9 & 86.8 \\
\hline $\mathrm{t}_{\mathrm{cr}}[\mathrm{s}]$ & 26.3 & 59.7 & 28.1 & 63.8 & 34.8 & 79.2 & 18.7 & 42.4 & 55.6 & 118.2 \\
\hline \multicolumn{11}{|c|}{$\begin{array}{l}\text { Constants used in performing the calculation: } \mathrm{a}_{\mathrm{p}}=3.35 \times 10^{-4} \mathrm{~cm}, \mu_{0}=0.028 \text { poise, } \mathrm{k}=1.38 \times 10^{-16} \mathrm{~g} \mathrm{~cm}^{2} / \mathrm{s}^{2} \mathrm{~K}, \mathrm{~T} \\
=298.15 \mathrm{~K}, \phi_{\mathrm{b}}=0.0243 \mathrm{vol} / \mathrm{vol}, \mathrm{I}_{11}=0.0474\left(\phi_{\mathrm{c}}=0.65\right) \text { and } 0.1077\left(\phi_{\mathrm{c}}=0.75\right) \text {, and } \mathrm{I}_{12}=0.545\left(\phi_{\mathrm{c}}=0.65\right) \text { and } \\
0.642\left(\phi_{\mathrm{c}}=0.75\right) \text {. }\end{array}$} \\
\hline
\end{tabular}

Steady-state models for crossflow filtration, in general, attempt to model the balance between particle deposition and cake growth. It is possible that this balance had not yet been achieved within $\sim 100$ hours of operation. To investigate the likelihood of this occurring in the experimental system, a model prediction of the time a steady-state flux would be reached $\left(t_{s s}\right)$ made by Song (Song, 1998) was calculated using the experimental parameters. The steady-state prediction has the following form:

$$
t_{s s}=0.351\left(\frac{L}{D_{0}^{2} \gamma}\right)^{2 / 3}\left(\frac{c_{0}}{c_{g}-c_{0}}\right)^{2 / 3}\left(\frac{c_{g}}{c_{0}}\right)\left(\frac{\Delta P-\Delta P_{c}}{r_{c}}\right)
$$

where $D_{0}$ is the diffusion coefficient, $c_{0}$ and $c_{g}$ are the bulk and gel concentrations of the solid phase (in volume fraction), $\Delta P_{c}$ is the critical pressure for cake formation, and $r_{c}$ is the specific cake resistance. Since the expression in Eq. 6 was originally written for laminar flow, some substitutions were made for quantities that were estimated using turbulent methods. For instance, instead of the molecular diffusion coefficient, the eddy diffusion coefficient for particles was calculated using the approach outlined in Altunbas et al (Altunbas et al., 2002), i.e.,

$$
\begin{gathered}
\frac{D_{T P}}{D_{T}}=0.0155\left(\frac{\tau U_{m}}{v}\right)^{1 / 2}\left(\frac{\varepsilon}{D}\right)^{0.094}, \text { and } \\
D_{T}=0.0285 v(\mathrm{Re})^{4 / 5}
\end{gathered}
$$

where $U_{m}=U_{n o m}, \varepsilon$ is the surface roughness, $v$ is the kinematic viscosity, and $\tau$ is relaxation time of the particles (for Stokesan particles, $\tau=4 \rho_{p} a_{p}^{2} / 18 \mu$ for a particle density of $\rho_{p}$ ). The quantity 
$D_{T P}$ (the eddy diffusivity of particles) was substituted for $D_{0}$ in Eq. 6 to provide a better estimate of the effective diffusivity of the particles.

Altunbas et al. also recommended a method to estimate the shear rate in turbulent flow, and this is given by the expression

$$
\gamma \sim \frac{4 U^{*}}{R}=\frac{0.8 U_{m}}{(\operatorname{Re})^{1 / 8} R}
$$

where $R$ is the radius of the filter tube ( $U^{*}$ is the friction velocity). This is an estimate based on the Blasius equation for turbulent flow. Using Eqs. 7 - 9 in conjunction with Eq. 6, the steadystate times for the conditions of the five tests were calculated. They ranged between 1.4 and 4.1 minutes, depending on the transmembrane pressure and the axial velocity (see Table 4). This is in stark contrast to what was observed experimentally.

Table 4. Results of the calculation of $t_{s s}$ using values of $\gamma, D_{T}$, and $D_{T P}$. The sensitivity of $t_{s s}$ to orders of magnitude changes in $\gamma$ and $D_{T P}$ are also shown.

\begin{tabular}{|c|c|c|c|c|c|}
\hline Test & S1T1 & S1T2 & S1T3 & S1T4 & S1T5 \\
\hline$\gamma\left(\right.$ Eq. 9) $\left[\mathrm{s}^{-1}\right]$ & 167 & 186 & 147 & 167 & 167 \\
\hline$D_{T}(\mathrm{Eq} .8)\left[\mathrm{m} \mathrm{s}^{-1}\right]$ & $2.28 \times 10^{-4}$ & $2.52 \times 10^{-4}$ & $2.04 \times 10^{-4}$ & $2.28 \times 10^{-4}$ & $2.28 \times 10^{-4}$ \\
\hline$D_{T P}$ (Eq. 7) $\left[\mathrm{m} \mathrm{s}^{-1}\right]$ & $4.50 \times 10^{-6}$ & $5.30 \times 10^{-6}$ & $3.74 \times 10^{-6}$ & $4.50 \times 10^{-6}$ & $4.50 \times 10^{-6}$ \\
\hline$t_{s s}[\mathrm{~min}]$ & 2.7 & 2.0 & 3.8 & 4.1 & 1.4 \\
\hline$t_{s s}(0.1 \gamma)[\mathrm{min}]$ & 12.6 & 9.5 & 17.6 & 18.9 & 6.3 \\
\hline$t_{s s}\left(0.1 D_{T P}\right)[\mathrm{min}]$ & 58.6 & 43.9 & 81.7 & 87.9 & 29.3 \\
\hline$t_{s s}\left(0.1 \gamma, 0.1 D_{T P}\right)[\mathrm{min}]$ & 272 & 204 & 379 & 408 & 136 \\
\hline \multicolumn{6}{|c|}{$\begin{array}{l}\text { Constants used in the calculation of } t_{s s} \text { (Eq. 6): } \\
L=0.6096 \mathrm{~m}[2 \mathrm{ft}], c_{0}=\phi_{b}=0.0243 ; c_{g}=0.1466 ; \Delta P=\text { nominal TMP of test; } \Delta P_{c}=2.6 \times 10^{-5} \\
\left.\mathrm{~Pa} ; r_{c}=3.9 \times 10^{8} \mathrm{~kg} \mathrm{~m}^{-3} \mathrm{~s}^{-1} \text { (estimated using Carmen-Kozeny equation with } \varepsilon=0.85\right) .\end{array}$} \\
\hline
\end{tabular}

To observe the sensitivity of the calculation to the input parameters estimated for turbulent flow, a few additional calculations were performed using Eq. 6. These are also shown in Table 4, where $\gamma, D_{T P}$, and both $\gamma$ and $D_{T P}$ were reduced by an order of magnitude. Even the case where both parameters are reduced by an order of magnitude results in a $t_{s s}$ on the order of a few hours. 
The disagreement between the Eq. 6 predictions of a short time to achieve steady-state flux (relative to the 100-h experiment) and the experimental data (absence of steady-state) implies that the transport mechanisms are more complicated than a balance between cake growth and particle back-transport/suspension.

The comparison with the steady-state time predicted by the model of Song (and likely others, as many are based on similar principles) illustrates how a classical prediction of filter flux does not describe the phenomena observed with the specific filter media/simulant combination used in these experiments. This could be because most theories were developed for laminar flow conditions and assume a particulate that is spherical, monodisperse, and not as chemically complex as the simulant used in these experiments. Thus, when performing the calculations given by previously developed theories, many parameters were estimated either by using a turbulent flow analogue or a simplification of the physics, i.e. using the d50 to represent an "average" particle size. A different crossflow model, whether based on different principles or a more complex formulation, appears to be needed.

Interestingly, Song (Song, 1998) also provides a model for time-dependent flux in infinite crossflow filtration (i.e., a filter of infinite length, or dead-end filtration), which predicts a decline to zero flux over time. This is similar to what was observed in this work. The transient flux model is given by the expression

$$
J_{p}=e^{-\alpha t} \frac{\Delta P}{R_{m}}+\left(1-e^{-\alpha t}\right)\left(\frac{\Delta P-\Delta P_{c}}{R_{b m}}\right)\left[1+\frac{2 r_{c}\left(\Delta P-\Delta P_{c}\right)}{R_{b m}^{2}} \frac{c_{0}}{c_{g}} t\right]^{-1 / 2}
$$

where $J_{p}$ is the predicted flux, $t$ is time, $\alpha$ is a blocking coefficient, and $R_{m}$ and $R_{b m}$ are the resistances of the clean and blocked membrane, respectively. When physically realistic parameters are entered into the model of Eq. 10, the prediction of the flux is in reasonable agreement with the experimental data; for one such example using the S1T1 data, see Table 5 (for the input parameters) and Figure 10 (for the comparison). Figure 10 also demonstrates (see the logarithmically scaled plot in particular), the model of Eq. 10 does not completely represent 
the flux behavior over the entire time period. The model has some subtle curvature that is not present in the data, and it does not predict the flux accurately at short times ( $<1 \mathrm{~h}$ elapsed time). The model is also very sensitive to the parameters that were chosen; for instance, changing the particle radius $a_{p}$ to $2 \times 10^{-6} \mathrm{~m}$ appreciably reduces the quality of the fit (the root-mean squared error increases from $8.5 \times 10^{-7}$ to $4.6 \times 10^{-6}$ ). However, the good agreement with the chosen parameters implies that the crossflow filter and simulant used in this work was experiencing flux degradation more typical of a dead-end filtration process rather than a crossflow process. Other classical dead-end filtration models, i.e. Ruth's Law (Ruth et al., 1933) or the blocking laws of Hermia (1981) may also represent the experimental data similarly.

Table 5. Input parameters used to generate the model prediction curve for the S1T1 data shown in Figure 10 using Eq 10.

\begin{tabular}{|r|c|}
\hline Parameter & $\begin{array}{c}\text { Value Used for Fitting } \\
\text { S1T1 Experiment }\end{array}$ \\
\hline$c_{0}$ & 0.0243 \\
\hline$a_{p}[\mathrm{~m}]$ & $3 \times 10^{-6}$ \\
\hline$v_{0}\left(J_{0}\right)\left[\mathrm{m} \mathrm{s}^{-1}\right]$ & $5.35 \times 10^{-5}$ \\
\hline$\alpha=0.75 v_{0} c_{0} / a_{p}\left[\mathrm{~s}^{-1}\right]$ & 0.32 \\
\hline$\Delta P_{c}[\mathrm{~Pa}]$ & $3.6 \times 10^{-5}$ \\
\hline$R_{m}=\Delta P / J_{0}\left[\mathrm{~Pa} \mathrm{~s} \mathrm{~m}{ }^{-1}\right]$ & $5.16 \times 10^{9}$ \\
\hline$R_{b m}=\Delta P / J_{b p, 0}\left[\mathrm{~Pa} \mathrm{~s} \mathrm{~m}{ }^{-1}\right]$ & $7.21 \times 10^{9}$ \\
\hline
\end{tabular}




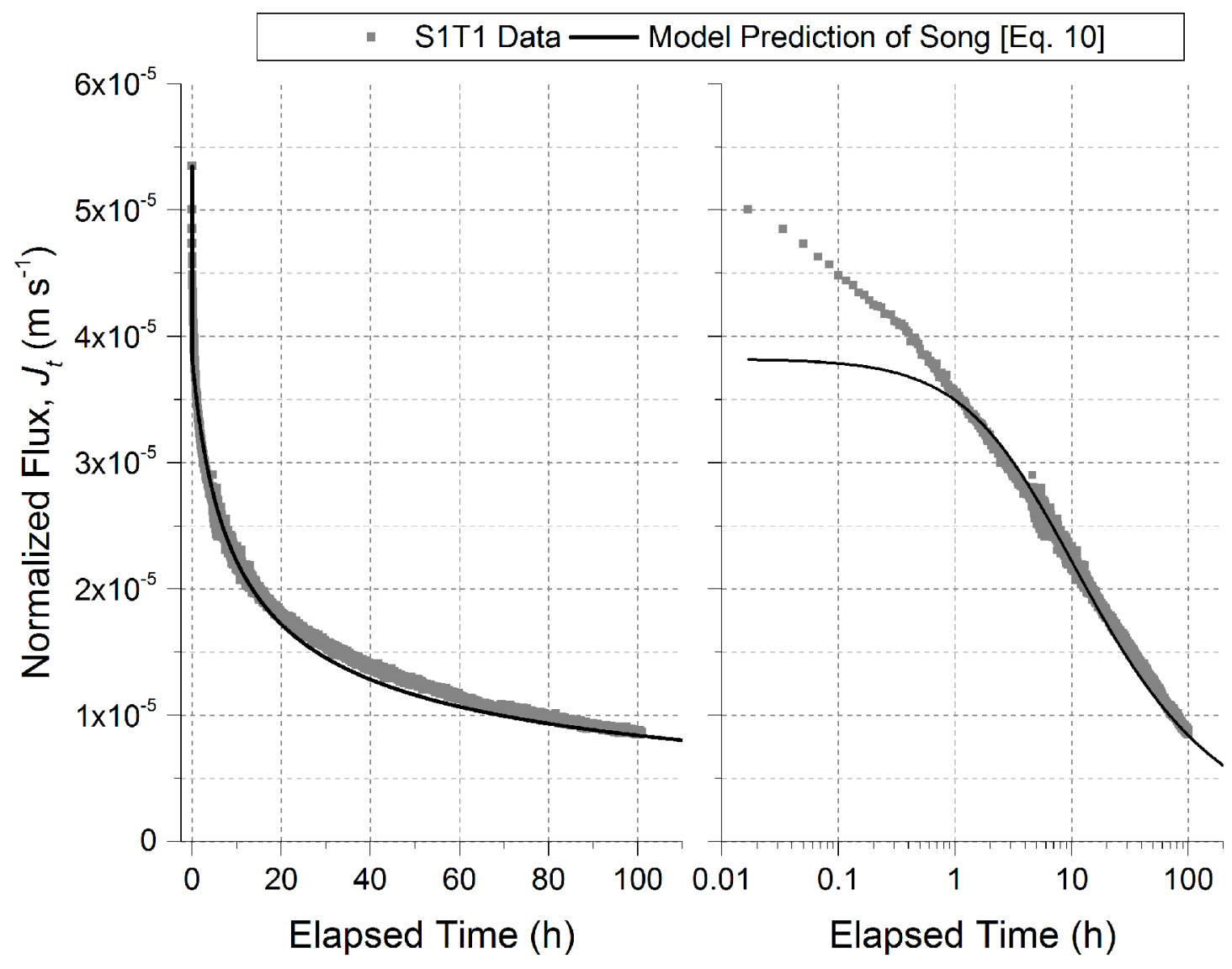

Figure 10. Comparison of the dead-end filtration model of Song (Song, 1998) with the experimental data $\left(J_{t}\right)$ from Test S1T1 (squares). The comparison is made on both linear (left) and logarithmic (right) ordinates to illustrate features of the comparison.

\section{Conclusions}

A series of long-time tests were performed with a sintered metal crossflow filter using a waste slurry simulant. Within the range of parameters studied, the filter flux was observed to have similar flux decay regardless of the axial velocity (though all experiments where the velocity was varied were conducted in the fully turbulent regime). The transmembrane pressure affects the magnitude of the rate of flux decay, with larger TMP resulting in greater decline in the flux. Based on the filter performance data collected before and after backpulsing was applied, the 
decline in flux is caused by a combination of reversible and irreversible fouling mechanisms. The irreversible mechanism had a smaller effect and occurs on a much shorter time scale than the reversible mechanism, which is assumed to be principally caused by some combination of cake formation, growth, and maturation.

Crossflow filtration is designed to achieve a balance between particle deposition and resuspension/back-transport via the application of the crossflow, and numerous studies suggest it would be expected that the flux would achieve a steady-state value. Comparison of experimental data with selected existing theories suggests that the cake should have begun forming at short times (on the order of minutes) and a steady state flux achieved shortly thereafter. However, this was not observed in the experiments. Reasonable agreement was obtained between the data and a model prediction using a dead-end filtration model developed by Song (Song, 1998) and careful choice of some input parameters. This suggests that, at least for the combination of simulant, filter media, and operating conditions used in this study, the cake was constantly evolving (increasing in thickness, compacting, migrating into the filter pores, etc.) over a long time period of operation. A model that incorporates the dynamic evolution of a cake layer (possibly borrowing from dead-end filtration principles), could handle more complex simulant mixtures, and is appropriate for a fully turbulent crossflow is the subject of future work.

\section{Acknowledgements}

The authors gratefully acknowledge the contributions of PNNL staff members Amanda Johnsen, Amanda Casella, Galen Brooks, Eugene Ngai, and Rick Aaroe, who helped conduct the experiments described in this paper. Brian Riley performed the microscopy presented in Figure 9 and his contribution is also appreciated. The work described in this article was performed by Pacific Northwest National Laboratory, which is operated by Battelle for the U.S. Department of Energy under Contract DE-AC05-76RL01830. This work was funded by the U.S. Department of Energy through the Office of Environmental Management. 


\section{References}

Altunbas, A., Kelbaliyev, G., Ceylan, K., 2002. Eddy diffusivity of particles in turbulent flow in rough channels. J Aerosol Sci 33, 1075-1086.

Benkahla, Y.K., Ould-Dris, A., Jaffrin, M.Y., Si-Hassen, D., 1995. Cake growth mechanism in cross-flow microfiltration of mineral suspensions. J. Membr. Sci. 98, 107-117.

Billing, J.M., Daniel, R.C., Kurath, D.E., Peterson, R.A., 2009. Bench-Scale Filtration Testing in Support of the Pretreatment Engineering Platform (PEP). PNNL-18673, Pacific Northwest National Laboratory, Richland, WA.

Blake, N.J., Cumming, I.W., and Streat, M., 1992. Prediction of steady state crossflow filtration using a force balance model. J. Membr. Sci 68, 205-216.

Chang, D-J., Hsu, F-C., and Hwang, S-J., 1995. Steady-state permeate flux of cross-flow microfiltration. J. Membr. Sci. 98, 97-106.

Daniel, R.C., Billing, J.M., Bontha, J.R., Brown, C.F., Eslinger, P.W., Hanson, B.D., Huckaby, J.L., Karri, N.K., Kimura, M.L., Kurath, D.E., Minette, M.J., 2010. EFRT M-12 Issue Resolution: Comparison of Filter Performance at PEP and CUF Scale. PNNL-18498, Rev. 1, Pacific Northwest National Laboratory, Richland, WA.

Daniel, R.C., Billing, J.M., Luna, M.L., Cantrell, K.J., Peterson, R.A., Bonebrake, M.L., Shimskey, R.W., Jagoda, L.K., 2009. Characterization of Filtration Scale-Up Performance. PNNL-18117, Pacific Northwest National Laboratory, Richland, WA.

Daniel, R.C., Billing, J.M., Russell, R.L., Shimskey, R.W., Smith, H.D., Peterson, R.A., 2011. Integrated pore blockage-cake filtration model for crossflow filtration. Chemical Engineering Research and Design 89, 1094-1103.

Defrance, L., Jaffrin, M.Y., 1999. Reversibility of fouling formed in activated sludge filtration. J. Membr. Sci. 157, 73-84.

Geeting, J.G.H., Hallen, R.T., 2005. Filtration, Washing, and Caustic Leaching of Hanford Tank AZ-101 Sludge. Separation Science and Technology 40, 1 - 15.

Hasan, A., Peluso, C.R., Hull, T.S., Fieschko, J., and Chatterjee, S.G., 2013. A surface-renewal model of cross-flow microfiltration. Brazilian Journal of Chemical Engineering 30, 167-186. 
Herman, D., Poirier, M., Fowley, M., Keefer, M., Huff, T., Greene, W., and Gilmour, J., 2011. Testing of the Second Generation SpinTek Rotary Filter. Presented at Waste Management 2011 Conference, March 7-11, 2011, Phoenix, AZ.Hermia, J., 1981. Constant Pressure Blocking Filtration Laws - Application to Power-Law Non-Newtonian Fluids. Trans. Ins. Chem. Eng. 59, 183-187.

Huisman, I.H., Elzo, D., Middelink, E., Trägårdh, A.C., 1998. Properties of the cake layer formed during crossflow microfiltration. Colloids and Surfaces A: Physicochemical and Engineering Aspects 138, 265-281.

Hwang, S-J., Chang, D-J., and Chen, C-H., 1996. Steady state permeate flux for particle crossflow filtration. The Chemical Engineering Journal 61, 171-178.

Kim, J., DiGiano, F.A., 2009. Fouling models for low-pressure membrane systems. Separation and Purification Technology 68, 293-304.

Mann, N.R., Todd, T.A., 2000. Crossflow filtration testing of INEEL radioactive and nonradioactive waste slurries. Chemical Engineering Journal 80, 237-244.

Nash, C.A., Saito, H.H., Wilmarth, W.R., 2003. Strontium and transuranic precipitation and crossflow filtration of a large Hanford Tank 241-AN-102 sample. Separation Science and Technology 38, 3189-3213.

Nguyen, T-A., Yoshikawa, S., and Ookawara, S., 2014. Steady state permeate flux estimation in cross-flow ultrafiltration of protein solution. Separation Science and Technology 49, 1469-1478.

Ripperger, S., Altmann, J., 2002. Crossflow microfiltration - state of the art. Separation and Purification Technology 26, 19-31.

Rorabacher, D.B., 1991. Statistical treatment for rejection of deviant values - critical values of Dixon Q parameter and related subrange ratios at the 95-percent confidence level. Anal. Chem. 63, 139-146.

Rubow, K.L., Jha, S., 1999. Sintered Metal Microfiltration Media, 17th Annual Membrane Technology/Separations Planning Conference, Newton, Massachusetts.

Ruth, B.F., Montillion, G.H., and Montonna, R.E., 1933. Studies in Filtration - II. Fundamental Axiom of Constant-Pressure Filtration. Ind. Eng. Chem. 25, 153-161.

Russell, R.L., Billing, J.M., Smith, H.D., Peterson, R.A., 2009a. Validation of Ultrafilter Performance Model Based on Systematic Simulant Evaluation. Ind. Eng. Chem. Res. 48, 1007710086. 
Russell, R.L., Peterson, R.A., Buchmiller, W.C., Rinehart, D.E., and Cantrell, K.J., 2009 b. Results of Aging Tests of Vendor-Produced Blended Feed Simulant. PNNL-18291, Pacific Northwest National Laboratory, Richland, WA.

Scheele, R.D., Brown, G.N., and Kurath, D.E., 2009. Scale-Up, Production, and Procurement of PEP Simulants. PNNL-18678, Pacific Northwest National Laboratory, Richland, WA.

Schonewill, P.P., Daniel, R.C., Russell, R.R., Shimskey, R.W., Burns, C.A., Billing, J.M., Rapko, B.M., and Peterson, R.A., 2012. Development of an S-Saltcake Simulant Using Crossflow Filtration as a Validation Technique. Separation Science and Technology 47, 20982107.

Sethi, S., Wiesner, M.R., 1997. Modeling of transient permeate flux in cross-flow membrane filtration incorporating multiple particle transport mechanisms. J. Membr. Sci. 136, 191-205.

Song, L.F., 1998. Flux decline in crossflow microfiltration and ultrafiltration: mechanisms and modeling of membrane fouling. J. Membr. Sci. 139, 183-200.

Ye, Y., Chen, V., 2005. Reversibility of heterogeneous deposits formed from yeast and proteins during microfiltration. J. Membr. Sci. 265, 20-28.

Zhang, M., Song, L., 2000. Mechanisms and Parameters Affecting Flux Decline in Cross-Flow Microfiltration and Ultrafiltration of Colloids. Environ. Sci. Technol. 34, 3767-3773. 


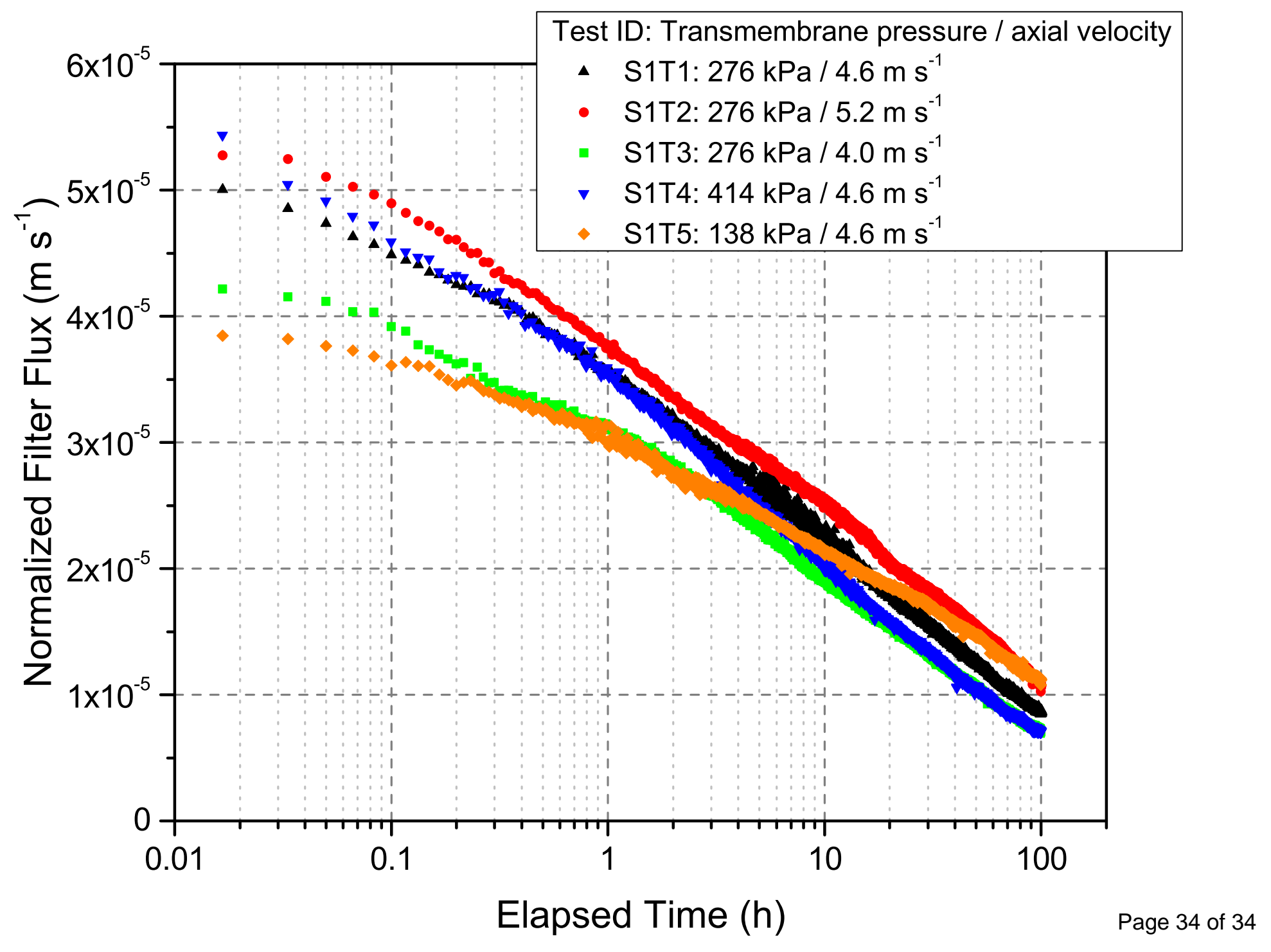

Test ID: Transmembrane pressure / axial velocity

S1T2: $276 \mathrm{kPa} / 5.2 \mathrm{~m} \mathrm{~s}^{-1}$

- S1T3: $276 \mathrm{kPa} / 4.0 \mathrm{~m} \mathrm{~s}^{-1}$

- S1T4: $414 \mathrm{kPa} / 4.6 \mathrm{~m} \mathrm{~s}^{-1}$

S1T5: $138 \mathrm{kPa} / 4.6 \mathrm{~m} \mathrm{~s}^{-1}$

Elapsed Time (h)

Graphical Abstract

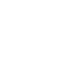
(1)

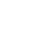

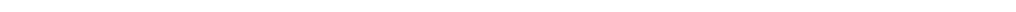

